\title{
Utilização de Microondas em Tecnologia da Madeira
}

\author{
Pedroti, M.V.M.; Mendonça, J. P. C.; Carreiro, G. D.; Souza, C. G. F.; Maffioletti, F. D.; \\ Alexia, B. M.; Schiavo, V.; Pinheiro, C. J. G. ${ }^{1}$ \\ 1 Departamento de Engenharia Rural, Universidade Federal do Espírito Santo, Alegre, ES, Brasil. \\ *e-mail:m.pedroti@gmail.com
}

\begin{abstract}
Resumo
A secagem da madeira é indispensável para a maioria dos fins para os quais é destinada. Contudo a retirada de água da madeira, sem os devidos cuidados, pode acarretar em defeitos na mesma. $O$ processo mais utilizado na secagem da madeira é a estufa por $48 \mathrm{~h}$. Com intuito de acelerar o processo de secagem da madeira este trabalho utilizou um forno de micro-ondas com potência de consumo de 700 watts. Na secagem por micro-ondas o principal mecanismo é o aquecimento por rotação dipolar. Após a calibração do forno as amostras de madeira, com dimensões $2 \times 5 \times 3 \mathrm{~cm}$, passaram por testes de secagem com tempos de 20 segundos e 50 repetições, 30 segundos e 37 repetições e 50 segundos e 28 repetições. Sendo o tempo de 50 segundos o mais eficiente na secagem da madeira, além de ter o menor número de repetições.
\end{abstract}

\begin{abstract}
Wood drying is indispensable for most of the purposes for which it is intended. However the removal of water from the wood, without proper care, can lead to defects in the same. The process most used in drying the wood is the greenhouse for $48 \mathrm{~h}$. In order to accelerate the wood drying process, this work used a microwave oven with a consumption power of 700 watts. In microwave drying the main mechanism is dipole rotation heating. After the furnace calibration, the wood samples, measuring $2 \times 5 \times 3 \mathrm{~cm}$, underwent drying tests with a time of 20 seconds and 50 repetitions, 30 seconds and 37 repetitions and 50 seconds and 28 repetitions. Being the time of 50 seconds the most efficient in the drying of the wood, besides having the smaller number of repetitions.
\end{abstract}

Keywords: Microwave, Heat Transfer, Wood.

\section{Introdução}

A secagem da madeira é indispensável para a maioria dos fins para os quais é destinada, por exemplo, o aumento da resistência à deterioração por organismos biológicos e o aumento da resistência mecânica. Sendo a secagem a retirada de substâncias voláteis dos materiais, no caso da madeira requer cuidado uma vez que a retirada de água da madeira pode acarretar em defeitos.

Existem diversos métodos secagem de madeira por estufa. A secagem pode ser em estufa industrial por 48 h ou em estufa convencional onde o tempo médio de secagem da madeira recém-cortada é de 30 dias, mas esse tempo pode ser reduzido com a realização de uma pré-secagem ao ar por 60 a 90 dias. Uma alternativa para redução de tempo é a secagem por micro-ondas [1].

Apesar de antigo (começou a ser usado na Segunda Guerra Mundial) o método de secagem de madeira por micro-ondas tem muito a ser pesquisado e discutido.
Com o intuito de conhecer mais o método de secagem por micro-ondas o presente trabalho objetivou secar madeiras de Eucalyptus utilizando micro-ondas e verificar a qualidade das mesmas.

$\mathrm{Na}$ secagem por micro-ondas, o principal mecanismo de aquecimento é o aquecimento por rotação dipolar. Com a incidência das micro-ondas nas moléculas polares a orientação randômica é desfeita. Quando não há incidência as moléculas retornam a orientação inicial. Mas, logo a seguir são atingidas novamente pelas micro-ondas em sentido contrário ao anterior com a incidência de um campo elétrico de polaridade inversa. O campo elétrico leva ao alinhamento e desalinhamento dos dipolos milhões de vezes por segundo devida a sua alternância de polaridade. Esse processo leva a uma transferência de calor no material devido à transformação de elétrica em energia potencial e consequentemente em energia térmica pelo material [2]. 


\section{Metodologia}

Neste trabalho foram utilizados, um forno de microondas, da marca Philco modelo pms18n2 com capacidade de 18 litros e potência de 700 Watts, uma balança analítica, um termopar e amostras de madeira, com dimensões $2 \times 5 \times 3 \mathrm{~cm}$.

Incialmente os 15 blocos foram saturados em tonel cheio de água por 45 dias com o objetivo de saturar a amostra em $100 \%$ de humidade. A seguir dividimos as amostras em 3 blocos com 5 tocos cada.

Cada toco teve a sua massa inicial verificada. Após esse processo o primeiro bloco teve 50 irradiações de 20 segundos. O segundo bloco teve 37 irradiações de 30 segundos. O terceiro bloco teve 28 irradiações de 50 segundos. Nos intervalos de cada irradiação todos os blocos eram pesados a fim de verificar se a humidade do mesmo estava em torno de $13 \%$.

\section{Discussão dos resultados}

Os resultados mostraram-se satisfatórios nos três blocos. Embora um ou outro toco tenham tido o problema de rachaduras no topo por estarem posicionados no ponto de maior incidência das microondas.

As irradiações de 50 segundos mostraram os melhores resultados pelo menor tempo de trabalho (Figura 1).

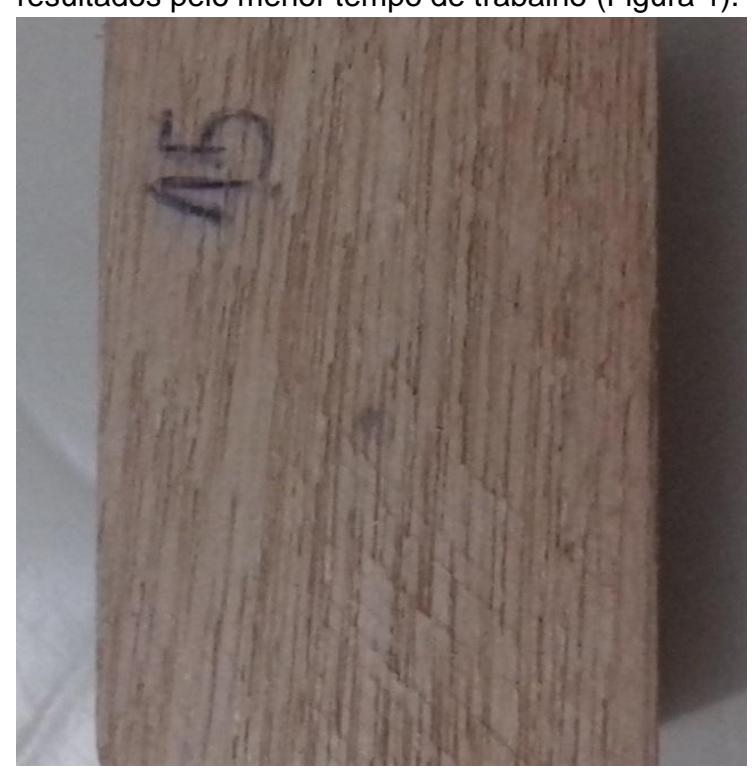

Figura 1: Imagem da amostra 15 após 28 irradiações de 50 segundos.

Assim, nos abriram precedentes para aumentar o tempo de cada irradiação e assim diminuir o número de repetições. Isso encurtaria o tempo de exposição da madeira. Os intervalos ainda se mostram crucias, mesmo em irradiações de curto tempo, para que a água da madeira não chegue a entrar em ebulição e assim provocar mais rachaduras de topo e internas.

\section{Conclusão}

Podemos concluir que o trabalho alcançou o seu objetivo de secar madeira utilizando micro-ondas. Apesar dos percalços citados na discussão quase todas as amostras alcançaram os $13 \%$ de humidade.

\section{Agradecimentos}

Os autores agradecem ao Departamento de Ciências Florestais e da Madeira pelo apoio.

\section{Referências}

\author{
Teses ou dissertações \\ [1] FREDERICO, J. N. F. Modelagem da Transferência \\ de Calor em Madeira de Pinus sp.. Dissertação \\ (Trabalho de Conclusão de Curso), Colegiado de \\ Engenharia Industrial Madeireira, DCFM/CCAE/ \\ Universidade Federal do Espírito Santo, ES, 2011.
}

[2] BRODIE, G. I. Innovative Wood Drying. Applying Microwave and Solar Technologies to Wood Drying. Saarbrucken: VDM Verlag, 2008. 